\title{
LIFTING CAPACITY ENHANCEMENT OF A CRAWLER CRANE BY IMPROVING STABILITY
}

\author{
A.A. Shaikh \\ Sardar Vallabhbhai National Institute of Technology, Department of Mechanical Engineering, Surat, Gujarat, India \\ e-mail: aas@med.svnit.ac.in \\ Dineesh Kumar D \\ S.D. Material Handlers Pvt. Ltd., Surat, Gujarat, India; e-mail: dineesh@syamadynamic.com
}

\begin{abstract}
The lifting capacity of a crawler crane is limited by its stability and structural strength. This paper analyzes the stability factor by calculating tipping loads at various load radii for a particular boom length. It shows that the tipping load decreases with an increase in the load radius. A new structural frame is proposed to extend out the superstructure counterweight of the crane. With such a proposed arrangement, it is shown that the lifting capacity of the crane, limited by stability, increases. Static structural analysis of the proposed structural frame is performed using ANSYS workbench software.
\end{abstract}

Keywords: crawler crane, stability, tipping load, lifting capacity

\section{Introduction}

The requirement for lifting in the construction industry is ever increasing. Crane manufacturers are constantly working on at achieving new heights in the lifting industry. Although higher capacity cranes are available, capacity enhancement of the existing cranes especially at longer radii will reduce the dependency on higher capacity cranes, which in turn will reduce costs of project construction. This will also cut down the capital investment of construction companies by avoiding the necessity of purchasing higher capacity cranes and, thereby, having an option to invest in other areas.

The load lifting capacity of a crawler crane is determined by the crane stability and its structural strength. There have been previous investigations on the tip over stability of the cranes and on the crane dynamics. Rauch et al. (2013) investigated the tip over stability analysis of mobile boom cranes with swinging payloads and presented the process for conducting stability analysis. Klinger (2014) studied the failure of cranes attributable to wind induced vibrations of tension bars leading to fatigue fractures. Wang et al. (2015) investigated stability of geometrically nonlinear slender frame structures of crawler cranes. Trąbka (2014) analyzed the influence of change in the number of flexible structural components of telescopic cranes. Savkovic et al. (2014) studied the stress distribution and deformation in the contact zone between segments of the telescopic boom of a hydraulic truck crane. Kilicslan et al. (1999) determined the maximum possible payload for a mobile crane that was kept in a fixed position by stabilizing arms while transferring the payload. Towarek (1998) studied dynamic stability of a boom crane influenced by flexible soil foundation. Chin et al. (2001) investigated effects of platform motion on the dynamic stability of a boom crane. Research studies on dynamic responses of a crane during various motions were demonstrated by Posiadała et al. $(1990,1991)$, Posiadała (1997), Sun and Kleeberger et al. (2003), Sun et al. (2005), Sun and Liu (2006), Jerman et al. (2004). However, it was found that the research study in the area of improving the lifting capacity of cranes had not developed appreciably. 
In this paper, an effort is made to improve the lifting capacity of a crawler crane limited by stability conditions. The stability analysis of an $80 \mathrm{MT}$ crawler crane with a $18 \mathrm{~m}$ lattice boom is carried out to find out the standing moment of the crane. The proposed structural frame attached to the crane superstructure is modeled to support the counterweight, which can be extended or retracted. The new lifting capacity of the crane with the extended counterweight is calculated, and static structural analysis is done for the proposed structural frame using ANSYS workbench software.

\section{Design aspects}

\subsection{Stability calculations}

A three dimensional model of an 80 MT Demag CC280 crawler crane is made using modeling software ProE as depicted in Fig. 1. To do this, the field work has been carried out to collect the dimensional data of major structural parts of the machine and two dimensional drawings have been made using Autodesk Autocad software.

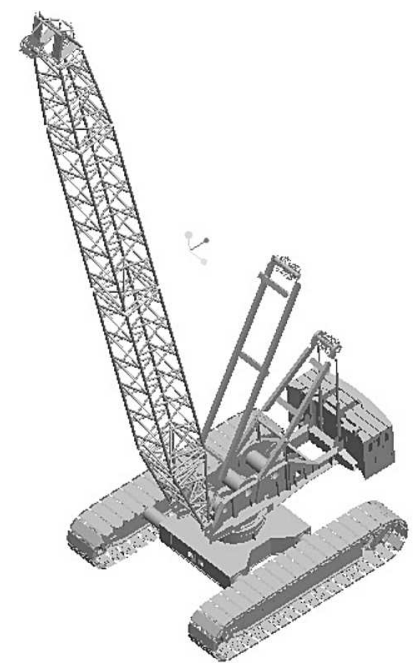

Fig. 1. 3D model of 80MT Demag CC 280 crawler crane

The predominant factor controlling load ratings for cranes is stability against tipping. The tipping load is the hook load at a specified radius about a line called the tipping fulcrum, which causes the crane to tip. A crane will tip when the overturning moment (moment of the load and boom about the tipping fulcrum) becomes close to or equal to the crane resisting moment (moment of the machine weight about the tipping fulcrum). The crane rating is based on taking the percentage of the tipping load. As per standard ASME (B30.5, 2011), the crawler crane load rating is 75 percent of the tipping load.

The crawler tracks are loose cast steel and their purpose is to provide runways for the track rollers and distribute the machine weight and load to the supporting surfaces. The track rollers define the position of the side fulcrum. When operating over the front and rear, the tipping fulcrum is located on the tilting edges defined by the connecting lines between the front and rear driving or idler sprockets. The sideways tilting edges are the connecting lines between the outer rollers. For calculation of $360^{\circ}$ crane working operation, the tilting fulcrum is considered to be on the tipping circle having radius of the shortest distance between the crane slewing centre and various tipping edges.

The weight and centre of gravity locations of various crane components are obtained from the 3D model of the crane. The tilting edges and tipping circle of the crane are obtained as shown in Fig. 2. 


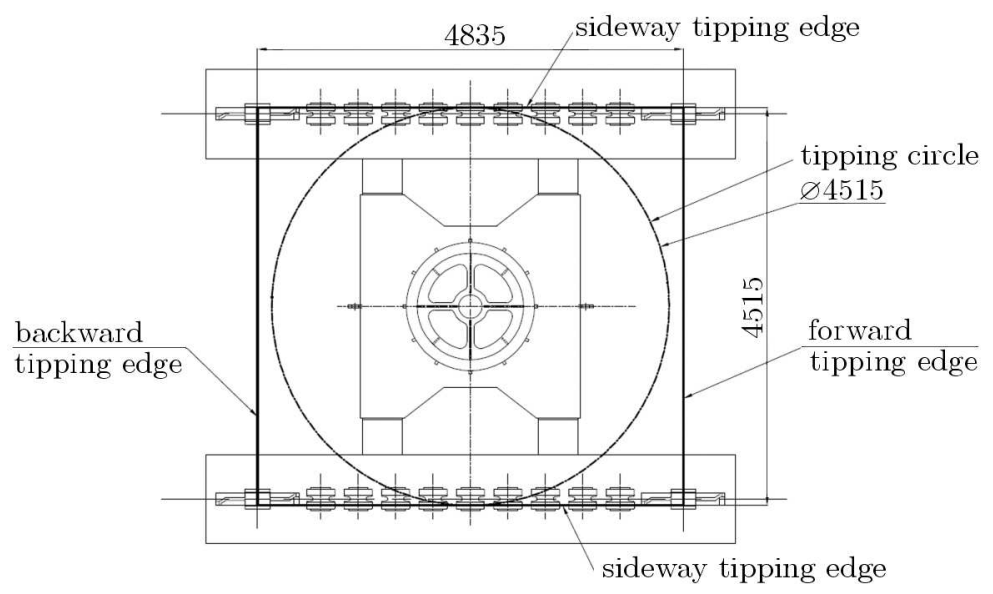

Fig. 2. Tipping edges and tipping circle of the crane - plan view

The selected crane can be configured with a boom length ranging from the minimum of $9 \mathrm{~m}$ to the maximum $54 \mathrm{~m}$. For performing stability analysis and considering the complexity of the larger boom, a boom length of $18 \mathrm{~m}$ is selected, which is two times basic boom length. Crane standing moments and stability load ratings are calculated at seven different load radii $(R)$ using the weights of crane parts and its centre of gravity (C.G.) locations as shown in Fig. 3.

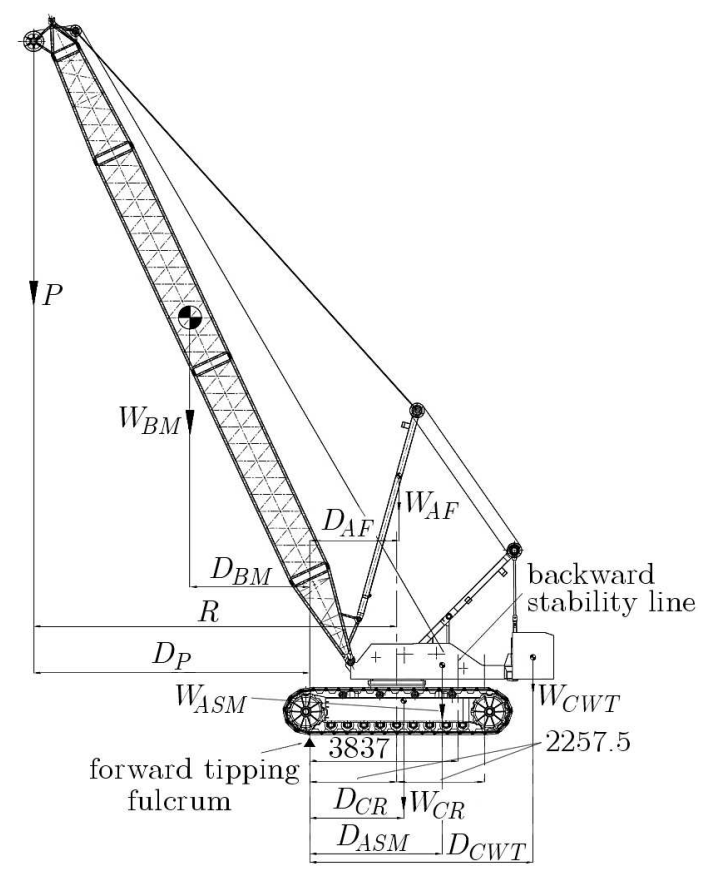

Fig. 3. Weights and centre of gravity (C.G.) locations of various crane parts

Standing moment $\left(M_{C R}[\mathrm{kN} \mathrm{m}]\right)$ of the crane is calculated from the following formula

$$
M_{C R}=W_{C R} D_{C R}+W_{C W T} D_{C W T}+W_{A F} D_{A F}+W_{B M} D_{B M}
$$

where $W_{C R}$ is the weight of the crane superstructure and carbody, $D_{C R}$ - distance between the tipping fulcrum and C.G. of the crane superstructure and carbody, $W_{C W T}$ - weight of the counterweight, $D_{C W T}$ - distance between the tipping fulcrum and C.G. of the counterweight, $W_{A F}$ - weight of the $A$-frame, $D_{A F}$ - distance between the tipping fulcrum and C.G. of $A$-frame, $W_{B M}$ - weight of the boom, $D_{B M}$ - distance between the tipping fulcrum and C.G. of the boom. 
The distance $\left(D_{A S M}[\mathrm{~m}]\right)$ between the tipping fulcrum and C.G. of the total crane assembly is obtained from

$$
D_{A S M}=\frac{M_{C R}}{W_{A S M}}
$$

where $W_{A S M}$ denotes the weight of the total crane assembly.

The tipping load $(T L[\mathrm{kN}])$ of the crane is

$$
T L=\frac{M_{C R}}{D_{P}}
$$

where $D_{P}$ is the distance between the tipping fulcrum and Hook load centre.

The rated load $(P[\mathrm{kN}])$ limited by stability of the crane is obtained from

$$
P=75 \% T L
$$

\begin{tabular}{|c|c|c|c|c|c|c|c|c|c|c|}
\hline \multicolumn{3}{|c|}{ Case } & Unit & 1 & 2 & 3 & 4 & 5 & 6 & 7 \\
\hline \multicolumn{3}{|c|}{ Boom length } & $\mathrm{m}$ & 18 & 18 & 18 & 18 & 18 & 18 & 18 \\
\hline \multicolumn{3}{|c|}{ Load radius $(R)$} & $m$ & 4 & 5 & 7 & 9 & 11 & 14 & 16 \\
\hline \multirow{8}{*}{$\sum_{4}$} & \multirow{2}{*}{$\begin{array}{l}\text { Crane super- } \\
\text { structure and } \\
\text { carbody }\end{array}$} & $W_{C R}$ & $\mathrm{kN}$ & 55.5 & 355.5 & 355.5 & 355.5 & 55.5 & 55.5 & 355.5 \\
\hline & & $D_{C R}$ & $\mathrm{~m}$ & 529 & 529 & .529 & 529 & .529 & .529 & 2.529 \\
\hline & \multirow{2}{*}{$\begin{array}{l}\text { Counter- } \\
\text { weight }\end{array}$} & $W$ & $\mathrm{kN}$ & 88.3 & 08.3 & 208.3 & 208.3 & 208.3 & 208.3 & 208.3 \\
\hline & & $D_{C}$ & $\mathrm{~m}$ & 5.712 & 5.712 & 5.712 & 5.712 & 5.712 & 5.712 & 5.712 \\
\hline & \multirow{2}{*}{$A$-frame } & $W_{A F}$ & $\mathrm{kN}$ & 7.64 & 7.64 & 7.64 & 7.64 & 7.64 & 7.64 & 7.64 \\
\hline & & $D_{A F}$ & $\mathrm{~m}$ & 3.747 & 3.507 & 2.992 & 2.429 & 1.81 & 0.742 & -0.113 \\
\hline & \multirow{2}{*}{ Boom } & $W_{B}$ & $\mathrm{kN}$ & 29.6 & 29.6 & 29.6 & 29.6 & 29.6 & 29.6 & 29.6 \\
\hline & & $\overline{D_{B M}}$ & $\overline{\mathrm{m}}$ & -0.12 & -0.67 & $\overline{-1.77}$ & -2.88 & -3.99 & -5.671 & -6.808 \\
\hline \multicolumn{3}{|c|}{ Standing moment $M_{C R}$} & $\mathrm{kN} \mathrm{m}$ & 2114 & 2096 & 2059 & 2022 & 1985 & 1927 & 1886 \\
\hline \multirow{2}{*}{\multicolumn{2}{|c|}{$\begin{array}{c}\text { Crane } \\
\text { assembly }\end{array}$}} & $W_{A S I}$ & $\mathrm{kN}$ & 601.1 & 601.1 & 601.1 & 601.1 & 601.1 & 601.1 & 601.1 \\
\hline & & $D_{A S M}$ & $\mathrm{n}$ & 3.517 & 3.487 & 3.426 & 3.365 & 3.302 & 3.205 & 3.138 \\
\hline \multicolumn{3}{|c|}{$\begin{array}{l}\text { Load distance from tipping } \\
\text { fulcrum } D_{P}\end{array}$} & $\mathrm{~m}$ & 1.742 & 2.742 & 4.742 & 6.742 & 8.742 & 11.742 & 13.742 \\
\hline \multicolumn{3}{|c|}{ Tipping load $(T L)$} & $\mathrm{kN}$ & 1213.6 & 764.4 & 434.3 & 300.0 & 227.0 & 164.1 & 137.3 \\
\hline \multicolumn{3}{|c|}{ Rated load $(P)$} & $\mathrm{kN}$ & 910.2 & 573.3 & 325.7 & 225.0 & 170.3 & 123.1 & $\overline{103.0}$ \\
\hline
\end{tabular}

The calculated values of the tipping load $(T L)$ and rated load $(P)$ are shown in Table 1.

Table 1. Tipping and rated loads of the crane in the red arrangement

AAA - Weight of the assembly and C.G. distance from tipping line

The stability of a crawler crane is governed by the standing moment of the crane. To increase the standing moment of the crane, counterweights (ballasts) are arranged at the rear end of the slewing platform or superstructure of the crane. The limit of the maximum counterweight is determined by the backward stability of the free standing crane. The backward stability of a crane is its ability to resist overturning in the direction opposite to the boom point while in the unloaded condition. The resistance to backward overturning is reflected in the margin of backward stability. According to standard ASME (B30.5, 2011), the minimum backward stability condition for crawler cranes is that the horizontal distance between the centre of gravity of the crane assembly and the axis of rotation shall not exceed $70 \%$ of the radial distance from the axis of rotation to the backward tipping fulcrum in the least stable direction. Since the counterweight is designed based on the backward stability of the crane at the minimum possible boom length 
and maximum possible boom angle, the backward stability of the crane increases with an increase in the boom length and load radius as C.G. of the crane assembly moves towards the forward tipping fulcrum.

The maximum allowable standing moment $\left(M_{C R}^{\max }[\mathrm{kNm}]\right)$ is obtained when the centre of gravity of the crane lies at the backward stability line

$$
M_{C R}^{\max }=W_{A S M} D_{B S}
$$

where $D_{B S}$ is the distance between the forward tipping fulcrum and the backward stability line, $[\mathrm{m}]$.

The backward stability line lies at a distance of $70 \%$ of the radial distance from the axis of rotation to the backward tipping fulcrum

$$
D_{B S}=2.2575+2.2575 \cdot 70 \%=3.837
$$

\subsection{Stability calculations with the proposed structural frame}

In the existing form, the counterweight of the crane is fixed at the rear end of the crane superstructure. The proposed structural frame is modeled using ProE software, which is attached to the bottom of the crane superstructure, wherein the counterweight is placed on top of it as shown in Fig. 4.

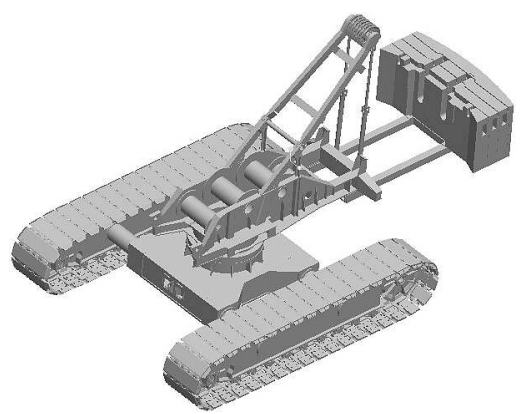

Fig. 4. 3D model of the crane assembly with an extended counterweight on the structural frame

This structural frame along with the counterweight is extendable and retractable. For a particular load radius, the structural frame along with the counterweight is extended correspondingly to the load radius so as to obtain the maximum possible standing moment considering the backward stability conditions. With an increase in the load radius, the counterweight is extended outwards and, if the load radius is decreased, the counterweight is retracted to the position corresponding to that load radius. The structural frame can be extended or retracted using a hydraulic cylinder with controls correlated with the safe load indicator or load moment indicator device of the crane. The position of the counterweight can be accurately controlled using length sensors and load moment indicator devices of the crane.

Considering the proposed structural frame and C.G. of various crane parts as shown in Fig. 5, where $W_{C W T}^{\prime}$ is the weight of the counterweight including the weight of the structural frame, $D_{C W T}^{\prime}[\mathrm{m}]$ - distance between the tipping fulcrum and C.G. of the counterweight including the structural frame, $W_{A S M}^{\prime}$ - weight of the crane assembly including the weight of the structural frame, $D_{A S M}^{\prime}$ - distance between the tipping fulcrum and C.G. of the crane assembly including the structural frame.

To obtain the maximum possible standing moment, the counterweight is extended outwards to a distance corresponding to the load radius as shown in Fig. 5.

It is obtained by the following formula

$$
D_{C W T}^{\prime}=\frac{M_{C R}^{\max }-\left(M_{C R}-W_{C W T} D_{C W T}\right)}{W_{C W T}^{\prime}}
$$




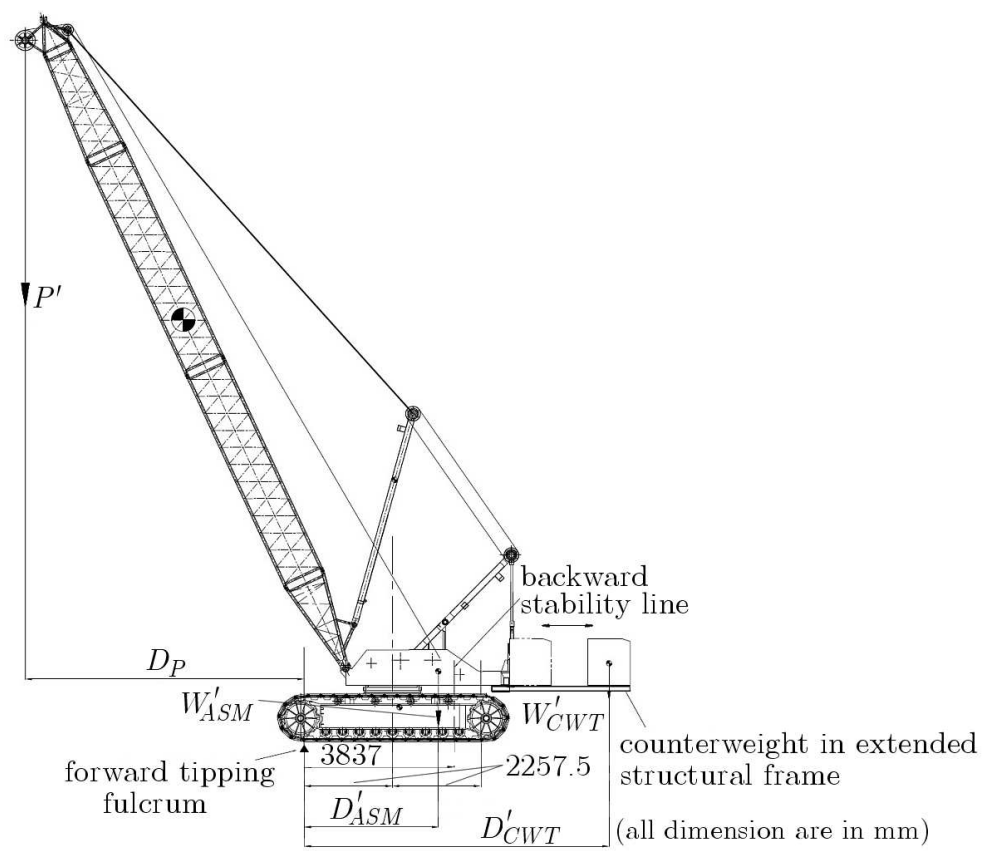

Fig. 5. Weights and C.G. of various crane parts in an extended counterweight position

The distance $D_{C W T}^{\prime}$ obtained from Eq. (2.7) satisfies the backward stability condition from standard ASME B30.5. The centre of gravity of the crane will be inside the backward stability line when the counterweight is in extended position. When there is a sudden release of load while the counterweight is in extended position, the backward stability margin will provide the overturning resistance to withstand the impact of the sudden release of load.

With the counterweight in an extended position, new tipping loads $\left(T L^{\prime}\right)$ and new rated load $\left(P^{\prime}\right)$ limited by stability are recalculated as shown in Table 2 . The graph showing a comparison of the new rated load $\left(P^{\prime}\right)$ with the extended counterweight and rated load $(P)$ without the extended counterweight for various load eadius $(R)$ is plotted in Fig. 6.

The calculations are performed for seven cases where the load radius of the crane changes from $4 \mathrm{~m}$ to $16 \mathrm{~m}$.

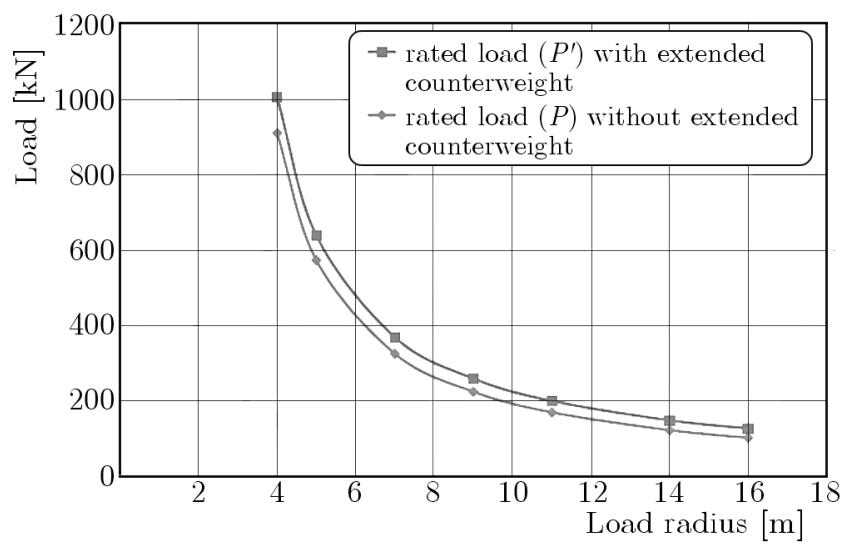

Fig. 6. Rated load versus load radius $(R)$ with and without the extended counterweight

\subsection{Static structural analysis}

The proposed structural frame will be under maximum loading when it is extended completely outwards with the counterweight as in case 7 . The static structural analysis of the structural 
Table 2. Tipping and rated loads of the crane with the extended counterweight

\begin{tabular}{|c|c|c|c|c|c|c|c|c|c|c|}
\hline \multicolumn{3}{|c|}{ Case } & Unit & 1 & 2 & 3 & 4 & 5 & 6 & 7 \\
\hline \multicolumn{3}{|c|}{ Boom length } & $\mathrm{m}$ & 18 & 18 & 18 & 18 & 18 & $\overline{18}$ & 18 \\
\hline \multicolumn{3}{|c|}{ Load radius $(R)$} & $\mathrm{m}$ & 4 & 5 & 7 & 9 & 11 & 14 & 16 \\
\hline \multirow{8}{*}{$\sum$} & \multirow{2}{*}{$\begin{array}{c}\text { Crane super- } \\
\text { structure and } \\
\text { carbody } \\
\end{array}$} & $\overline{\overline{W_{C R}}}$ & $\overline{\mathrm{kN}}$ & 355.5 & 355.5 & 355.5 & 355.5 & 355.5 & 355.5 & 355.5 \\
\hline & & $D_{C R}$ & $\mathrm{~m}$ & 2.529 & 2.529 & 2.529 & 2.529 & 2.529 & 2.529 & 2.529 \\
\hline & \multirow{2}{*}{$\mathrm{BBB}$} & $W_{C W T}^{\prime}$ & $\mathrm{kN}$ & 215.6 & 215.6 & 215.6 & 215.6 & 215.6 & 15.6 & 215.6 \\
\hline & & $D_{C W T}^{\prime}$ & $\mathrm{m}$ & 5.667 & 5.667 & \begin{tabular}{|l|}
5.667 \\
\end{tabular} & 5.667 & 5.667 & 5.667 & 5.667 \\
\hline & \multirow{2}{*}{$A$-frame } & $W_{A F}$ & $\mathrm{kN}$ & 7.6 & 7.6 & 7.6 & 7.6 & 7.6 & 7.6 & 7.6 \\
\hline & & $D_{A F}$ & $\mathrm{~m}$ & 3.747 & 3.507 & 2.992 & 2.429 & 1.81 & 0.742 & -0.113 \\
\hline & \multirow{2}{*}{ Boom } & $W_{B M}$ & $\mathrm{kN}$ & 29.6 & 29.6 & 29.6 & 29.6 & 29.6 & 29.6 & 29.6 \\
\hline & & $D_{B M}$ & $\mathrm{~m}$ & -0.12 & -0.669 & -1.77 & -2.876 & -3.988 & -5.671 & -6.808 \\
\hline \multirow{2}{*}{\multicolumn{2}{|c|}{$\begin{array}{c}\text { Crane } \\
\text { assembly }\end{array}$}} & $W_{A S M}$ & $\mathrm{kN}$ & 608.4 & 608.4 & 608.4 & 608.4 & 608.4 & 608.4 & 608.4 \\
\hline & & $D_{A S M}$ & $\mathrm{~m}$ & 3.528 & 3.498 & 3.438 & 3.377 & 3.315 & 3.219 & 3.153 \\
\hline \multicolumn{3}{|c|}{$\begin{array}{l}\text { Load distance from tipping } \\
\text { fulcrum } D_{P}\end{array}$} & $\mathrm{~m}$ & 1.742 & 2.742 & 4.742 & 6.742 & 8.742 & 11.742 & 13.742 \\
\hline \multicolumn{3}{|c|}{$\begin{array}{l}\text { Max. possible standing } \\
\text { moment }\left(M_{C R}^{\max }\right)\end{array}$} & $\mathrm{kN} \mathrm{n}$ & 2334.3 & 2334.3 & 2334.3 & 2334.3 & 2334.3 & 2334.3 & 2334.3 \\
\hline \multicolumn{3}{|c|}{$\begin{array}{l}\text { New counterweight distance } \\
\text { w.r.t max. standing } \\
\text { moment }\left(D_{C W T}^{\prime}\right)\end{array}$} & $\mathrm{m}$ & 6.540 & 6.624 & 6.794 & 6.966 & 7.140 & 7.409 & 7.596 \\
\hline \multicolumn{3}{|c|}{$\begin{array}{l}\text { New tipping load with } \\
\text { exten. counterweight }\left(T L^{\prime}\right) \\
\end{array}$} & $\mathrm{kN}$ & 1340.0 & 851.3 & 492.3 & 346.2 & 267.0 & 198.8 & 169.9 \\
\hline \multicolumn{3}{|c|}{$\begin{array}{l}\text { Rated load with extended } \\
\text { counterweight }\left(P^{\prime}\right)\end{array}$} & $\mathrm{kN}$ & 1005.0 & 638.5 & 369.2 & 259.7 & 200.3 & 149.1 & 127.4 \\
\hline
\end{tabular}

AAA - Weight of the assembly and C.G. distance from tipping line

BBB - Counterweight with extendable frame

frame is performed in this condition using ANSYS workbench software. The material properties of the structural frame are described in Table 3 (ThyssenKrupp Steel, 2005). The stress analysis of the structural frame is shown in Fig. 7.

Table 3. Material properties of the structural frame

\begin{tabular}{|c|c|c|c|c|}
\hline Steel grade & $\begin{array}{c}\text { Minimum yield } \\
\text { strength [MPa] }\end{array}$ & $\begin{array}{c}\text { Tensile strength } \\
{[\mathrm{MPa}]}\end{array}$ & $\begin{array}{c}\text { Modulus of } \\
\text { elasticity }\left[\mathrm{kN} / \mathrm{mm}^{2}\right]\end{array}$ & $\begin{array}{c}\text { Density } \\
{\left[10^{3} \mathrm{~kg} / \mathrm{m}^{3}\right]}\end{array}$ \\
\hline \hline N-A-XTRA (M) 700 & 700 & $770-940$ & 210 & 7.85 \\
\hline
\end{tabular}

\section{Results and discussions}

Table 1 reveals that the rated load limited by stability of the crane decreases with an increase in the load radius. As the load radius increases, the moment from the weight of the boom reduces the standing moment of the crane. Proportionately, the tipping load also decreases resulting in a reduction in the rated load capacity.

The calculated values described in Table 1 show that the standing moment of the crane is much below the maximum allowable standing moment calculated from Eq. (2.5). The difference between the maximum allowable standing moment $\left(M_{C R}^{\max }\right)$ and the standing moment $\left(M_{C R}\right)$ 


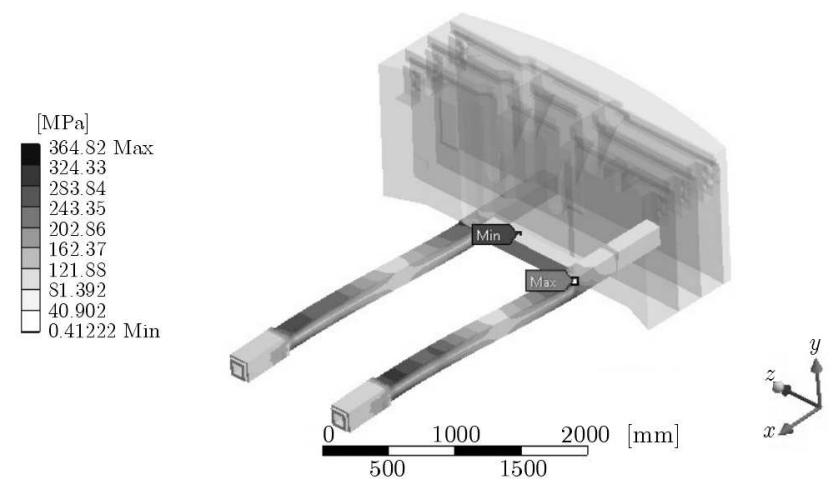

Fig. 7. Stress analysis of the proposed structural frame

of the crane increases with the load radius $(R)$ and boom length. It is mainly due to fact that the counterweight is designed and optimized to obtain the maximum possible standing moment when the crane is equipped with the minimum boom length and maximum boom angle. The difference in this case is due to the same reason that the counterweight has been designed for the crane boom length of $9 \mathrm{~m}$, which is the basic boom length of this crane, and at the maximum angle. In the present case, the crane is equipped with a $18 \mathrm{~m}$ boom length. Hence, the moment due to the weight of the additional $9 \mathrm{~m}$ boom reduces the standing moment of the crane, and it is further reduced with an increase in the load radius.

The graph shown in Fig. 6 reveals that the rated load of the crane, limited by the stability, increases by using a sliding structural frame. The structural frame is extended or retracted with respect to the corresponding load radius. When the counterweight is extended outwards using the structural frame, C.G. of the crane assembly moves backwards closer to the backward stability line. It is observed that the standing moment of the crane increases to the maximum allowable standing moment by extending the structural frame with the counterweight. Finally, the tipping load and rated load are increased due to improvement of the standing moment of the crane.

The structural stress analysis of the proposed structural frame shown in Fig. 8 reveals that the maximum value of stress obtained is $365 \mathrm{~N} / \mathrm{mm}^{2}$, which is below the permissible limit of $466 \mathrm{~N} / \mathrm{mm}^{2}$ accorging to standard SAE J987 (2003).

\section{Conclusions}

Based on the three dimensional model of a crawler crane and standard ASME B30.5 (2011), the standing moment and tipping loads of the crane are obtained. The maximum allowable standing moment of the crane is obtained from the backward stability condition specified in standard ASME B30.5. The proposed structural frame is modeled for extending and retracting the crane counterweight corresponding to the particular load radius. The tipping loads and lifting capacities of the crane with the extended counterweight at various radii are recalculated.

It is shown that the lifting capacity limited by the stability increases with making use of the proposed structural frame. By changing the fixed counterweight into a movable counterweight placed on the proposed sliding structural frame, the standing moment of the crane is improved to the maximum allowable standing moment. This furtherly enhances the tipping load and finally the lifting capacity of the crane. The lifting capacity of the crane, limited by stability, increases to the range of $10 \%$ to $24 \%$ with the use of the extended counterweight. It is also found that the percentage of the lifting capacity enhancement increases with increase of load radius. The compliance of the backward stability condition, according to standard ASME B30.5, ensures safety and stability of the crane with the extended counterweight. 


\section{Acknowledgements}

The authors appreciate the support provided by M/s. S. D. Material Handlers Pvt. Ltd. for this work.

\section{References}

1. Chin C., Nayfeh A.H., Abdel-Rahman E., 2001, Nonlinear dynamics of a boom crane, Journal of Vibration and Control, 7, 199-220

2. Jerman B., Podrzaj P., Kramar J., 2004, An investigation of slewing-crane dynamics during slewing motion-development and verification of a mathematical model, International Journal of Mechanical Sciences, 46, 729-750

3. Kilicslan S., Balkan T., Ider S.K., 1999, Tipping load of mobile cranes with flexible booms, Journal of Sound and Vibration, 223, 4, 645-657

4. Klinger C., 2014, Failure of cranes due to wind induced vibrations, Engineering Failure Analysis, 43, 198-220

5. Posiadala B., 1997, Influence of crane support system on motion of the lifted load, Mechanism and Machine Theory, 32, 1, 9-20

6. Posiadala B., Skalmierski B., Tomski L., 1990, Motion of the lifted load brought by a kinematic forcing of the crane telescopic boom, Mechanism and Machine Theory, 25, 547-555

7. Posiadala B., Skalmierski B., Tomski L., 1991, Vibration of load lifted by a truck crane with consideration of physical properties of rope, Machine Dynamics Problems, 2, 85-104

8. Rauch A., Sighose W., Fujioka D., Jones T., 2013, Tip - over stability analysis of mobile boom cranes with swinging payloads, Journal of Dynamic Systems, Measurement, and Control, 135, 3, 0310081-6

9. Savkovic M., Gasic M., Pavlovic G., Bulatovic R., Zdravkovic N., 2014, Stress analysis in contact zone between the segments of telescopic booms of hydraulic truck cranes, Thin-Walled Structures, 85, 332-340

10. Standard ASME B30.5-2011, Mobile and Locomotive cranes, Safety standard for Cable-ways, Cranes, Derricks, Hoists, Hooks, Jacks, and Slings

11. Standard SAE J987, 2003, Lattice Boom Cranes - Method of Test

12. Sun G., Kleeberger M., 2003, Dynamic responses of hydraulic mobile crane with consideration of the drive system, Mechanism and Machine Theory, 38, 1489-1508

13. Sun G., Kleeberger M., Liu J., 2005, Complete dynamic calculation of mobile crane during hoisting motion, Mechanism and Machine Theory, 40, 447-466

14. Sun G., Liu J., 2006, Dynamic responses of hydraulic crane during luffing motion, Mechanism and Machine Theory, 41, 1273-1288

15. ThyssenKrupp Steel, Material Specification 215, 2005-12, 1-4

16. TowAreK Z., 1998, The dynamic stability of a crane standing on soil during the rotation of the boom, International Journal of Mechanical Sciences, 40, 557-574

17. TrąBKA A., 2014, Dynamics of telescopic cranes with flexible structural components, International Journal of Mechanical Sciences, 88, 162-174

18. Wang G., QI Z., Kong X., 2015, Geometrical nonlinear and stability analysis for slender frame structures of crawler cranes, Engineering Structures, 83, 209-222 